\title{
ACTUALIDADES
}

Rov. Chil. Pediatr, 64 (5); 397-343, 1993

\section{Trasplante renal en pediatría. Experiencia en el Servicio de Nefrología Pediátrica del Hospital Necker des Enfants Malades, París, Francia}

\author{
Eduardo Wolff P. ${ }^{1 ;}$; Michel Broyer2; Marie France Gagnadoux ${ }^{2}$
}

\section{Kidney transplantation in cbildren}

\begin{abstract}
Successful kidney Iransplantation is considered to be the optlmal therophy for end slage renal disease in children. forty four renal transplanis, five from leverelated donor and thirty nine from codaver donor were performed along one year (november 1990 Ihroughou november 1991) of the Pedialrlc Nephrology Division, Necker-Enfanls Mialades Hospilal, Poris, France. Potlent corocteristics, donoreceplor histocompotibility, inmunosuppresive regimen, early and lote complications, grof rejection and comesponding theraphy ore described, together with groft funclion, clinical evolulion, general health conditions and complications of the fransplanled patients ot the time. Palients survival rate was $100 \%$ and grat survival rale was $89 \%$.
\end{abstract}

(Key words: kidney transplantalion.)

En el niño en insuficiencia renal crónica terminal (IRCt) el objetivo final de todo programa terapéutico es el trasplante renal, que debe ser realizado lo mass precozmente posible cuando se llega a la etapa terminal de la enfermedad. Toda otra opción terapéutica, sean tratamientos médicos de mantención o diversos procedimientos dialíticos, deben ser lo mas breve posible, debido al gran número y variedad de complicaciones que conllevan, entre ellas la frecuentemente mala tolerancia del niño a la diálisis, el retraso del crecimiento, la progresión y agravamiento de la enfermedad osea renal, anemia de difícil manejo, problemas inherentes a los accesos vasculares en la hemodiálisis, peritonitis en la perítoneodiálisis, etc. Además del impacto en lo somático, el nifio en diálisis desarrolla severos trastomos psíquicos, producto de su situación de dependencia, en un ambiente agravado por las manifestaciones neurológicas de la uremia. Finalmente, desde el punto de vista social, estas terapias a largo plazo

1. Médico. Unidad de Neftología, Hospital Luis Calvo Mackenno, Universidad de Chile. Clínica Las Condes.

2. Médico. Servicio de Nefrología Pediátrica, Hospital Necker des Enfants Malades, París, Francia. generan serios trastomos en la educación y las relaciones humanas del paciente como de su familia ${ }^{1}$.

Como consecuencia, en el mundo se tiende a disminuir el número de pacientes IRCt sometidos a diálisis y aumentar proporcionalmente el de pacientes trasplantados, especialmente en la última décrada, en que drogas inmunosupresoras nuevas y más eficaces han hecho del trasplante con rif́ón donado por paciente en muerte cerebral, la opción válida y éticamente más aceptada.

Los primeros trasplantes renales en niños se realizaron a mediados de los años sesenta en los Estados Unidos, principalmente con riñones de donantes vivos emparentados, cuyos resultados, al cabo de más de veinte años de seguimiento, son muy satisfactorios, con sobrevidas de $92 \%$ de los pacientes en los últimos cinco años y globales, en veinte años de evolución, de $79 \% 2,3$.

El objetivo de esta presentación es mostrar la experiencia adquirida en el Servicio de Nefrología Pediátrica del Hospital Necker des Enfants Malades, de París, durante el año 1991, en lo que se refiere al trasplante renal en el paciente pediátrico. En este servicio se inició el programa de trasplante en niffos a fines del año 1973 , empleando principalmente órganos de donantes en 
muerte cerebral; ha reunido actualmente la más grande experiencia de Europa, encontrándose además entre los centros más importantes del mundo en el manejo de este tipo de enfermos, llegando a 818 trasplantes a fines de 1991.

En los primeros 350 irasplantes, todos manejados con tratamiento inmunosupresor convencional (prednisona-azathioprina), la sobrevida de los injertos fue $79 \%$ a un año, $65 \%$ a cinco años, $45 \%$ a diez años. La sobrevida total de los pacientes fue, a su vez, $97 \%$ a un año, $93 \%$ a cinco años, $90 \%$ a diez años. En el año 1983 se agregó al tratamiento inmunosupresor la ciclosporina $A$ y posteriormente, en 1985, el suero antilinfocitario (SAL), lo que permitio mejorar la sobrevida actuarial -a 10 años- del injerto a cerca de $80 \%$ y a $95 \%$ la de los pacientes, disminuir el númcro y magnitud de los rechazos y de los efectos secundarios al tratamiento convenciona $1^{4-7}$.

Si se agrupan las causas que habitualmente llevan a estos niños a la IRCt, en enfermedades adquiridas, glomerulopatías primarias y secundarias, afecciones genćticas, hipoplasia y displasia y trastorno de causa no precisada, vemos que en Chile éstas guardan proporciones que tienen cierta semejanza con cifras de países europeos y Estados Unidos, excepto en afecciones adquiridas potencialmente prevenibles, como la pielonefritis crónica y la nefropatía secundaria a malforma. ciones urológicas, que conforman en este país aproximadamente $44 \%$ del tolal de las causas, mientras que cn paises más desarrollados ćsta es sólo 20 a $30 \%{ }^{8-10}$.

La prevalencia de la insufíciencia renal crónica en niños era, en Chile, 9 por millón de habitantes en $1989^{11,12}$, comparable a las de Europa (7 casos por millón) y Estados Unidos (5 a 10 casos por millón). En Chile la incidencia calculada de IRCt es 0,7 por millón de habitantes por año. En Norteamérica se estima en aproximadamente 4500 nuevos casos por año el número de niños candidatos a trasplante renal y se realizan entre 500 y 700 trasplantcs anualmente t, $^{8-10}$. Todas estas cifras sirven para señalar la importancia cada vez más grande que adquierc el trasplantc como solución, en muchos casos definitiva, de estos enfermos.

Durante el período de noviembre 1990 a octubre 1991 se realizaron 44 trasplantes, 19 mujeres y 25 hombres, entre 3 y 18 arjos de edad, pero sólo seis eran menores de 15 años. Las enfermedades que causaron la insuficiencia renal se describen en la tabla 1. En seis casos se tramba del segundo trasplante, debido a fracaso del anterior, por rechazo en tres pacientes $y$ por trombosis vascular en los otros. El período de diálisis previo al trasplante fue menor a un año en 11 casos; en veinte pacientes duró entre uno y tres años y en 13 más de tres años. Del total de trasplantes realizados, en 32 pacientes se efectuó nefrectomía bilateral de los riñones primitivos, por hipertensión arterial (n:28) y cistinosis (n: 4).

El origen del injerto fue en cinco casos (11\%) un donante vivo emparentado y en 39 (88\%) un donante cadáver. Estos últimos eran de la más diversas edades, entre ellos tres menores de un año y uno mayor de 60 años, siendo la principal causa de muerte los accidentes, traumatismos encefalocraneanos y los accidentes vasculares cerebrales, todos con función renal normal al momento de la extracción del organo y sin anteccdentes que contraindicaran la donación.

La histocompatibilidad entre donante y receptor fue muy variada, como se muestra en la tabla 2, exigiéndose preferentemente el mínimo de incompatibilidađ en el antígeno clase II (DR); en nueve casos se compartian los dos haplo tipos, en 29 al menos uno y en sólo seis no se compartía ninguno, pero en éstos se exigió mejor compatibilidad del grupo de antígenos clase I (A-B).

Tabla 1

Causas de la insuficiencia renal terminal

\begin{tabular}{lll}
\hline Diagnostico & n & \% \\
\hline Glomerulopaúas & 9 & 20 \\
GEFS & 2 & \\
SNCR & 5 & \\
GNRP & 2 & \\
Uropatías inefropatía del reflujo) & 8 & 18 \\
Displasia - hipoplasia & 6 & 14 \\
Cistinosis & 5 & 11 \\
Nefronoptisis & 5 & 11 \\
Valvas - dísplasia & 4 & 9 \\
Síndrome de Alport & 2 & 4 \\
Nefropatía intersticial & 1 & 2 \\
Poiiquistosis & 1 & 2 \\
Enfermedad de Berger & 1 & 2 \\
Desconocida & 2 & 4 \\
\hline
\end{tabular}

GEFS: glomeruloesclerosis focal y segmentaria SNRC: sindrome nefrólico corticorresistente GNRP: glomerulonef ritis rápidamente progresiva 
En Francia la obtención de órganos para trasplante se dirige a través de un organismo nacional llamado "France Transplant", el cual la coordina desde cualquier hospital del país y otros de Europa a través de su conexión con el organismo internacional "Eurotransplant". Mediante este sistema los periodos de isquemia fría, que corresponden al tiempo transcurrido entrc la extracción del ơrgano y su implante en el receptor, fueron, en cinco casos, menores de 24 horas, en 21 entre 24 y $36 \mathrm{~h}$, en 12 entre 36 y 48 b y en dos se proiongo por más de $48 \mathrm{~h}$. Cabe destacar que un trasplante fue realizado con un órgano con 60 horas de isquemia fría, con buen resultado funcional final. El período de isquemia tibia, que corresponde al tiempo transcurrido entre la extracción del órgano del medio de conservación y su instalación dentro del abdomen y el despinzamiento de la arteria renal, y depende básicamente de la habilidad y experiencia del equipo quirúrgico, fue en la mayoría de los casos entre 30 y 50 minutos, pero en cuatro se prolongo más de 60 minutos.

El protocolo de tratamiento inmunosupresor puesto en práctica en el Hospital Necker des Enfants Malades desde 1987 considera el usa de triple terapia con corticoides, azatioprina y ciclosporina ${ }^{13-14}$.

Corticoides: metilprednisolona $2 \mathrm{mg} \cdot \mathbf{k g}$ iv una vez 30 minutos antes de la primera dosis de suero antilinfocitario, que se repite el segundo y lercer días, para luego pasar a prednisona oral el día 304 en dosis de $60 \mathrm{mg} \cdot \mathrm{m}^{2}$ (máximo $80 \mathrm{mg}$ ) hasta el día 6 , en que comienza una disminución progresiva de la dosis, para llegar a $30 \mathrm{mg} \bullet \mathrm{m}^{2}$ el día 30 después del trasplante, $15 \mathrm{mg} \cdot \mathrm{m}^{2}$ el día 60 y finalmente a $7.5 \mathrm{mg} \cdot \mathrm{m}^{2}$ al sexto mes; en casos seleccionados esta dosis, a partir del primer año, puede darse en días alternos.

Azathioprina: $2 \mathrm{mg} \cdot \mathrm{kg}$ iv en el preoperatorio inmediato y luego $1,5 \mathrm{mg} \cdot \mathrm{kg} \cdot$ dia en una dosis oral y adaptada según el recuento absoluto de glóbulos blancos.

Ciclosporina: se inicia a partir del sexto día en dosis de $1 \mathrm{mg} \cdot \mathbf{k g}$ - día en goteo continuo intravenoso, con el fin de obtener tasas sanguíneas entre 50 y $100 \mathrm{ng} / \mathrm{ml}$ (dosage monoclonal en radio inmunoensayo) hasta el dia 10 en que se aumenta la dosis hasta obtener tasas sanguíneas entre 150 y $200 \mathrm{ng} / \mathrm{ml}$ ( $\mathrm{y}$ entre 200 y $300 \mathrm{ng} / \mathrm{ml} \mathrm{si}$ cursa un rechazo), todo esto independiente de la funcionalidad del injerto. A partir del día 16 se cambia en tres dias sucesivos, y en forma progresiva, a vía oral (generalmente 3 veces a dosis en miligramos que recibía por via intravenosa). En el período de control posterior al día 30 se pretende mantener tasas sanguíneas entre 100 y 200 $\mathrm{ng} / \mathrm{ml}$, dosificando la ciclosporina en dos dosis diarias.

A partir de 1985 se agregó a este tratamiento triasociado, el suero antilinfocitario, el cual actualmente se administra durante los dicz primeros días, previa prueba cutánca de hipersensibilidad al medicamento (ATG Fresdenius o thymoglobulina Merieux). Se inicia en el pabellón operatorio en dosis de $0,05 \mathrm{ml} \cdot \mathrm{kg} \cdot$ día de ATG (el doble para thymoglobulina), se administra 0,1 ml de ATG diluido en $30 \mathrm{ml}$ de solución glucosada al $5 \%$, se pasa en cuatro horas y el resto de las dosis calculada en 8 horas, en perfusión continua por la fístula arteriovenosa. La dosis se pucde aumentar hasta $0,15 \mathrm{ml} \cdot \mathrm{kg}$ dependiendo de la respuesta en la cuantificación perifćrica del linfocito. Se suspende con trombopenia menor a 80 mil o leucopenia menor a $2000 / \mathrm{mm}^{3}$, cvidencia de infección viral o rechazo. Durante un período de tres años (1987 a 1990) se uso en forma alternada SAL y anticuerpos monoclonales contra subpoblaciones de linfocitos CD3 (ORT3), durante los primeros 10 a 15 días posteriores al trasplante, suspendiéndose el uso de este úlumo medicamento para la profilaxis inmediata después del trasplante, dejándolo como tratamiento contra el rechazo en casos resistentes a metilprednisolona.

Además del tratamiento inmunosupresor antes mencionado, se emplean otras drogas, como dopamina durante los 3 primeros días (en pacien-

\section{Tabla 2}

Calce de antigenos de histocompatibilidad

\begin{tabular}{|c|c|c|c|c|}
\hline $\begin{array}{l}\text { n de antígenos } \\
\text { DR compatibles }\end{array}$ & 0 & 1 & 2 & $\mathbf{n}$ \\
\hline \multicolumn{5}{|l|}{$\begin{array}{l}\text { n de antígenos } \\
\text { A'B compatibles }\end{array}$} \\
\hline $0:$ & 0 & 1 & 0 & 1 \\
\hline 1: & 2 & 8 & 4 & 14 \\
\hline 2: & 3 & 17 & 3 & 23 \\
\hline 3: & 1 & 1 & 0 & 2 \\
\hline $5:$ & 0 & 2 & 2 & 4 \\
\hline Total & 6 & 29 & 9 & 44 \\
\hline
\end{tabular}


tes anúricos y normotensos); antihistamínicos $\mathrm{H} 2$ en los mayores de 10 años o sometidos a cstrés intenso; analgésicos, anticoagulantes en los menores de 5 años o con antecedentes de trombosis y antivirales como profilaxis en los casos de donante con reacciones positivas para citomegalovirus.

Si se define la funcionalidad del injerto como el momento en que la creatininemia inicia su descenso espontáneo, en la gran mayoria ( $59 \%)$ de los casos, dentro de los cuales están los cinco Irasplantes de donante vivo, la creatininemia bajó en los 5 primeros dias; en $36 \%$ cl descenso ocurrió entre los 5 y 15 días y en solo el $5 \%$ (2 casos) el injerto comenzó a funcionar después de transcurridos 15 dias.

Durante el primer mes siguicnte al trasplante se presentaron 16 episodios de rechazo al injerto, de mayor o menor severidad, todos los cuales pudieron ser controlados con el tratamiento de metilprednisolona en pulsos $\left(1 \mathrm{~g} / \mathrm{m}^{2} \cdot 1.73\right)$ administrados cada 48 horas y por 3 veces. En un solo caso este tratamiento no dio resultado y la biopsia reveló un componente vascular importante en su patogenia, lo que motivo agregar anticuerpos monoclonales OKT3, con lo cual, luego de seis días de tratamiento y con dificultad, se logró controlar y obtener una función renal rclativamente accptable.

Se presentaron varjadas complicaciones, tanto en el periodo postoperatorio inmediato como más tarde en la evolución (tabla 3), destacando la hipertensión arterial como la más frecuente. De los 32 pacientes con doble nefrectomía, diez evolucionaron con hipertensión arterial leve, sicte con hipertensión moderada, tres con hipertensión severa y doce sin hipentensión. De los doce pacientes no sometidos a nefrectomía, cuatro evolucionaron con hipertensión leve, uno moderada, uno severa y seis sin hipertensión, pero ninguno de estos últimos tenia el antecedente de ella antes del trasplante. Hubo dos casos con complicaciones graves de origen vascular, uno sufrió sangramiento masivo de la anastomosis arterial, sin pérdida del injerto, y otro obstrucción parcial de la arteria renal, que fue tratada por vía endoarterial con buen éxito. En cinco casos de los 44 transplantes realizados $(11 \%)$ se debió realizar la nefrectomía del injerto precozmente, en tres por trombosis arterial, en caso por necrosis total del injerto y en otro por estallido renal. Destacable es un caso de una severa diabetes mellitus
Tabla 3

Complicaciones postoperatorias

\begin{tabular}{ll}
\hline Urologicas & $\mathbf{n}$ \\
Necrosis unión ureterovesical & 2 \\
Obsirucción unión ureterovesical & J \\
Uninoma & 1 \\
Necrosis de uréter & 1 \\
Retcnción urinaria por vejiga neurogénica & 1
\end{tabular}

Infecciosas

[nfección unnaria 10

Bactercmia

Infección por citomegalovirus

Otras (infección fissula aneriovenosa, peritonitis,

herpes bucal, Neumosistis carini, Rotavirus)

Yasculares

Sangramiento masivo de anastomosis

Obstrucción de artcria renal

Hipertensión arterial

Inicial: leve moderada 11 severa 6

Pemanente: leve moderada 9 severa

insulino-dependiente y a alta dosis, atribuible a la terapia corticoidal, la cual fue lentamente corigiendose según se disminuia la dosis de esteroides. Hubo un caso de recidiva inmediata de una hialinosis segmentaria y focal glomerular sobre el injerto que provocó una gran proteinuria y un síndrome nefrótico sin respuesta a pesar del tratamiento inmunosupresor propio del trasplante (metilprednisolona, ciclosporina y azathioprina). Esta paciente cvolucionó con lento y progresivo deterioro de la función del injerto a pesar de haber bajado la creatininemia en forma muy precoz y no haber presentado nunca un rechazo durante el tiempo en control.

Por último, en una evaluación realizada al final del período que abarca la serie (octubre de 1991), en $74 \%$ (n:29) de los pacientes sometidos a trasplante, la creatininemia era menor a 1 $\mathrm{mg} / \mathrm{dl}$, en $18 \%$ (n: 7) entre 1 y $1,5 \mathrm{mg} / \mathrm{dl}$, y en dos seguía cercana a $2 \mathrm{mg} / \mathrm{dl}$. Del total de los pacientes, $66 \%$ tenian hipertensión arterial, $33 \%$ de éstos en cifras leves de presión, $23 \%$ moderadas y en $10 \%$ (n: 4 ) la hipertensión arterial era 
severa, requiriendo terapia bi o triasociada de medicamentos antihipertensivos.

Desde hace algunos afios, en los hospitales pediátricos de los países más desartollados el trasplante renal se ha venido incorporando entre los procedimientos establecidos de tratamiento que se ofrecen al paciente en insuficiencia renal terminal, permitiendo sobrevida y rehabilitación de niños que antes morían o, en el mejor de los casos, vivían atados permanentemente a las diferentes modalidades de diálisis, con todos los inconvenientes de estas en los niños.

Los argumentos que hacen del trasplante renal el método terapéutico más indicado en estos enfermos son el mejor crecimiento en talla y peso; el control y detención de la enfermedad ósea renal; el cambio radical en el modo de vida con interpretación a y de la familia; mejor rendimiento escolar; buena tolerancia -en general- a los medicamentos inmunosupresores $y$, en el largo plazo, menores costes econ $\delta$ $\operatorname{micos}^{2-7}$.

En Francia la ley facilita enormemente la posibilidad de obtener organos de donantes en muerte cerebral, ya que considera a todos los ciudadanos potencialmente donantes, excepto a quienes en vida y en forma expresa han manifestado lo contrario. Adenás, es necesaria la autorización de los padres o la autoridad tutelar en caso de personas menores. Esto ha permitido que el trasplante sea actualmente un procedimiento frecuente, con el enome beneficio que esto significa para estos pacientes.

El servicio de nefrología pediátrica del Hospital Necker des Enfants Malades se encuentra muy proximo a completar mil trasplantes realizados, habiendo comenzado este programa en el ano 1973. Durante este último año se tealizaron 44 trasplantes, lo que da una cifra algo menor al promedio anual habitual. Hasta 1990 se habian realizado 39 trasplantes en niños menores de 5 años, todos pesaban más de $9 \mathrm{~kg} \mathrm{e}$, idealmente, se prefiere esperar manteniendo a los pacientes con diâlisis hasta que alcanzan un desartollo físico mínimo de 7 a $8 \mathrm{~kg}$ de peso y $75 \mathrm{~cm}$ de talla. Si bien en estos niños es posible realizar el trasplante con algunas precauciones, el riesgo de fracaso por trombosis arterial es importante, como también por otros problemas, fundamentalmente de técnica quirúrgica. Tomando las debidas precauciones, el resultado posterjor es excelente, en especial en términos de crecimiento $y$ rehabilitación. En este grupo de trasplantes realizados durante 1991, seis niños eran menores de 5 aftos y el menor tenía 3 años y todos cursaron muy buena evolución posterior.

El tiempo de espera en diálisis, previo al trasplante fue, en la mayoría de los casos, entre uno $y$ tres años $y$, en 13 pacientes, mayor a tres años. Casi la mitad de estos enfermos venían de otros países (africanos, árabes, de Europa oriental, etc.). con los cuales Francia tiene convenio de atención de salud, siendo estos los pacientes cuya espera es mayor.

Gran númeto de enfermos liega al trasplante renal despues de nefrectomía de uno de sus rifiones, para ser nefrectomizados del otro en el momento del trasplante. La principal indicación de la nefrectomía bilateral es el antecedente de hipertensión previa, y tiene por objeto evitar la participación de los riñones primitivos en la eventual hipertensión arterial posterior al trasplante, la cual constituye la principal complicación registrada en el seguimiento de estos enfermos. Con esta medida, además de disminuir la incidencia de la complicación disminuye la posibilidad de confusión en el diagnóstico etiopatogénico y en el tratamiento cuando ella se produce.

En relación a la histocompatibilidad entre donante y receptor, en el Hospital Necker des Enfants Malades no se hace en general gran exigencia, especialmente después de haber agregado ciclosporina al tratamiento inmunosupresor, excepto en pacientes sensibilizados por transfusiones sanguíneas o trasplantes previos, o en casos en que debe elegirse entre dos pacientes para un solo donante, cuando uno de los antecedentes importantes es la cantidad de compatibilidades e incompatibilidades, en especial del antigeno DR.

Los resultados obtenidos durante el periodo anual descrito son en general muy satisfactorios, destacando desde luego los que reciben un rinón de donante vivo, en quienes dicho descenso es casi inmediato luego del trasplante, sin necesidad de diálisis. En los pacientes en que el descenso de la creatininemia tarda más de 10 días no se detectó algún factor común dentro de sus antecedentes, de los que habitualmente se invocan para explicar la demora en la regulación de la función del injerto (tiempo de isquemia fría $y$ tibia, histocompatibilidad, incidentes operatorios, hipotensión, sangramientos, etc.). 
Los episodios de rechazo respondieron bien al tratamiento inmediato con bolos de metilprednisolona. En algunos casos especialmente severos se agregó terapia anticoagulante (por el eventual componente vascular en la patogenia del rechazo) y sólo en uno que no respondió fue necesario agregar anticuerpos monoclonales OKT3, con buena respuesta. Por lo general se prefiere realizar una biopsia renal o aspiración por punción, para medir la cantidad de células inflamatorias en la muestra obtenida, así fundamentar el rechazo y decidir el tratamiento que se empleará. Se prefiere hacer biopsia cuando ha transcurrido el primer mes y el paciente estŕ sin tratamiento anticoagulante.

Estos resultados, si bien muestran una instantánea de lo que ocurre durante un año en un importante centro nefrológico pediátrico en lo que respecta a trasplante renal, permiten tener una idea del estado actual de este procedimiento en el mundo. Ellos serán evidentemente variables de un centro a otro, dependiendo de numerosos factores que no es el momento de analizar en detaile, entre otros el protocolo inmunosupresor y la experiencia del equipo quirúrgico; tampoco los protocolos utilizados son los mismos hoy que hace 10 años. Con la utilización actual, ya sea del tratamiento secuencial de suero antilinfocitario y luego la inmunosupresión convencional (prednisona, azathioprina), ya sea la ciclosporina sola o asociada con los otros medicamentos, los resultados a un año son igualmente del orden de $85 \%$ a $90 \%$ de funcionalidad del implante. Con la introducción de la ciclosporina, más que mejorar la sobrevida del injerto, ha disminuido la cantidad de rechazos y mejora el crecimicnto de estos enfermos al permitir bajar la dosis de corticoides. Hay que hacer notar que a partir de 1985 la sobrevida de estos enfernos permanece cercana al $100 \%$ сл el conjunto de trasplantes realizados. Con el trasplante de donante vivo (Jo más frecuente en niños de nuestro país), las sobrevidas de injerto y de enfermos son 10 a $15 \%$ mejores que con riñón de cadáver, obteniéndose los mejores resultados entre familiares HLA idénticos, donde la funcionalidad sobrepasa generalmente de $90 \%$ a cinco años en centros experimentados.

En la mayoría de los casos se puede reiniciar una vida normal dos o tres mescs despućs de' trasplante, en dondc el paciente sólo debc recibir los medicamentos y asistir regularmente a sus controles, los cuales se van espaciando a medida que pasa el tiempo, y no aparezcan complicaciones, y sólo debe guardar algún tipo de precauciones, entre ellas las dietéticas, tipo de actividad física, evitar en lo posibie el contacto con personas con enfermedades contagiosas y otras.

La rehabilitación después del trasplante, como lo demuestran todos los estudios realizados, es excelente; más del $90 \%$ de estos niños o adolescentes siguen una escolaridad y una formación profesional o laboral completamente normal.

\section{Resumen}

El trasplante renal se ha constituido, en la última década, en la alternativa terapéutica de elección y muchas veces definitiva para el niño que llega a la condición de insuficiencia renal terminal. Cuarenta y cuatro trasplantes renales, cinco de ellos de donante vivo y treinta y nueve de donante cadáver, se realizaron durante un períolo de un arto (noviembre 1990 - noviembre 1991) en cl Servicio de Nefrología Pediátrica del Hospital Necker des Enfants Malades, Paris, Francia. Se analiza el grupo de pacientes en sus características clínicas, histocompatibilidad donante-receptor, tratamiento inmunosupresor, complicaciones precoces y tardías, rechazos al injerto, tratamiento antirrechazo utilizado y finalmente se describe una evaluación al tếrmjno del periodo de control en relación a funcionalidad de! injerto, características de su evolución, como también el estado general de los pacientes y sus complicaciones. La sobrevida de los pacientes fue del $100 \%$ y de los injertos del $89 \%$.

(Palabras clave: trasplante de riñón.)

\section{Referencias}

1. Delucchi $A$, Wolff E. Cano F el ai.: Hemodiâlisis crónica en nijos. Rev Chil Pediatr 1990: 61: 188193.

2. Lee HN, Méndez-Picón $G$, Posner MP: The siatus of rehabilitation, morbidity and mortality of long tern survivors of pediatrics kidncy transplants. Transplantation Proceedings 1989: 21: 1989-1991.

3. Potter $D$, Feduska $N$, Meltzer $J$ et al.: Twenty years of renal transplantation in children. Pediatrics 1986; 77 : 465-470.

4. Broyer M, Gagnadoux MF, Guest G, Niaudel P: Triple therapy including Cyclosporine A versus conventional 
regimen. A randornized prospective study in pediatric kidney transplantation. Transplantation proceedings 1987; 19: 3582-3585.

5. Broyer $M$, Gagnadokx MF, Guert $G$ el al.: Transplantation rénsle chez l'enfants. Analyse de 383 greffes réalisses a l'hopital des Enfants Malades de 1973 à 1984. In: Actuslites Néphrologiques de I'hopital Necker 1986, Paŕs. Flammarion Medicine Sciences, 1986; 3: $305 \cdot 330$.

6. Broyer $M$ : Kidney Iransplantation in children. Data from the EDTA Registry. Transplantation Procedins 1989; 21: $1985-1988$.

7. Broyer $M, G$ Gest $G$ : La croissance aprés tuansplantation rénale chez l'enfants. In: Joumées parisiemrtes de Ptdiatrie 1987, París. Flammarion Médicine Sciences $1987 ; 4: 135-143$.

8. Alexander S, Arbus $G, B$ But $X$ et al.: The 1989 repon of the North American Pediatric Renal Transplant Cooperative Study, Pediatr Nephrol 1990; 4: 542-543.
9. Curtis A, Sheldon MD, Richard $M$, Ehrlich MD: The challenge of pediatric renal transplantation. Dialog Pediatr Urol 1991; 14: 1-2.

10. Mc Enery PT, Stablein DM. A7bus GS and Tejani A: Renal Iransplantation in children. N Engl J Med 1992; 1326: 1727-1731.

11. Rodríguez $E$, Delucchi $A, C a n o F$ : Insuficiencia renal crónica en Chile. Rev Chil Pediatr 1990; 61:355-356.

12. Delucchi A, Cano F: Insuficiencis renal crónica. Rev. Chil Pediatr 1990; 61 (Supl. 1): 19-20.

13. Broyer M. Niandet P. Gagradowx M: Prolocolo inmunosupresor del trasplante con rinón cadáver, 1990. Protocolo de tratamiento del Servicio de Nefrologia Pediátrica. Hopital Necker des Enfants Malades. París. Francia. 1990; 1: 15-19.

14. Broyer $M$ : Hopital Necker Enfants Malades, Inserm U 192 Paris. Transplantation in Children. Simposio, III Congreso Latinosmericano de Nefrología Pediátrica. Buenos Aires, Argentina, 1992.

Esta publicación está disponible en copias de microfilms de 16 y $35 \mathrm{~mm}$ y microfichas de $105 \mathrm{~mm}$, las que pueden solicitarse a:

University Microfilms International

300 North Zeeb Road

Ann Arbor, Michigan 48106, USA.

This journal is also available in $16 \mathrm{~mm}$ microfilm, $35 \mathrm{~mm}$ microfilm and 105 mm microfilm copies through

University Microfilms International,

300 North Zeeb Road,

Ann Arbor, Michigan 48106. USA. 